Pacific Journal of 


\title{
ON THE UNIVALENCE OF SOME ANALYTIC FUNCTIONS
}

\author{
G. M. SHAH
}

Let

$$
f(z)=z+\sum_{k=n+1}^{\infty} a_{k} z^{k}
$$

and

$$
g(z)=z+\sum_{k=n+1}^{\infty} a_{k} z^{k}
$$

be analytic and satisfy

$$
\operatorname{Re}(f(z) /[\lambda f(z)+(1-\lambda) g(z)])>0
$$

or

$$
\begin{aligned}
|f(z) /[\lambda f(z)+(1-\lambda) g(z)]-1| & <1 \\
& \text { for }|z|<1,0 \leqq \lambda<1 .
\end{aligned}
$$

We propose to determine the values of $R$ such that $f(z)$ is univalent and starlike for $|z|<R$ under the assumption (i) $\operatorname{Re}(g(z) / z)>0$, or $\left(\right.$ ii) $\operatorname{Re}\left(z g^{\prime}(\boldsymbol{z}) / g(\boldsymbol{z})\right)>\alpha, 0 \leqq \alpha<1$.

We also consider the case when $n=1$ and $\operatorname{Re}(g(z) / z)>1 / 2$ and show that under condition $(a) f(z)$ is univalent and starlike for $|z|<(1-\lambda) /(3+\lambda)$.

2. LEMMA 1. If $p(z)=1+b_{n} z^{n}+b_{n+1} z^{n+1}+\cdots$ is analytic and satisfies $\operatorname{Re}(p(z))>\alpha, 0 \leqq \alpha<1$, for $|z|<1$, then

$$
p(z)=\left[1+(2 \alpha-1) z^{n} u(z)\right] /\left[1+z^{n} u(z)\right], \quad \text { for }|z|<1,
$$

where $u(z)$ is analytic and $|u(z)| \leqq 1$ for $|z|<1$.

Proof. Let

$$
F(z)=[p(z)-\alpha] /(1-\alpha)=1+c_{n} z^{n}+c_{n+1} z^{n+1}+\cdots .
$$

$F(z)$ is analytic and $\operatorname{Re}(F(z))>0$ for $|z|<1$ and hence

$$
h(z)=[1-F(z)] /[1+F(z)]=d_{n} z^{n}+d_{n+1} z^{n+1}+\cdots,
$$

is analytic and $|h(z)|<1$ for $|z|<1$. Thus, by Schwarz's lemma

$$
h(z)=z^{n} u(z),
$$

where $u(z)$ is analytic and $|u(z)| \leqq 1$ for $|z|<1$. Now equations (2), (3) and (4) prove (1).

Lemma 2. Under the hypothesis of Lemma 1 we have for $|z|<1$ 
$\left|z p^{\prime}(z) / p(z)\right| \leqq 2 n z^{n}(1-\alpha) /\left\{\left(1-|z|^{n}\right)\left[1+(1-2 \alpha)|z|^{n}\right]\right\}$.

Proof. Proceeding as in the proof of Lemma 1, we have in view of (3) and a result of Goluzin [1] that for $|z|<1$

$$
\left|h^{\prime}(z)\right| \leqq n|z|^{n-1}\left(1-|h(z)|^{2}\right) /\left(1-|z|^{2 n}\right) .
$$

Using (3), the inequality (5) takes the form

$$
\left|F^{\prime}(z)\right| \leqq 2 n|z|^{n-1} \operatorname{Re}(F(z)) /\left(1-|z|^{2 n}\right) .
$$

Hence, in view of (2),

$$
\left|p^{\prime}(z)\right| \leqq 2 n|z|^{n-1}[\operatorname{Re}(p(z))-\alpha] /\left(1-|z|^{2 n}\right)
$$

or,

$$
\left|z p^{\prime}(z) / p(z)\right| \leqq 2 n|z|^{n}\left(1-\alpha /(|p(z)|) /\left(1-|z|^{2 n}\right) .\right.
$$

Equation (4) gives

$$
|h(z)| \leqq|z|^{n} \quad \text { for }|z|<1,
$$

and hence, by virtue of (3),

$$
|F(z)| \leqq\left(1+|z|^{n}\right) /\left(1-|z|^{n}\right) \quad \text { for }|z|<1 .
$$

From (2) and (9),

$$
\begin{aligned}
|p(z)| & =|\alpha+(1-\alpha) F(z)| \\
& \leqq \alpha+(1-\alpha)|F(z)| \\
& \leqq\left[1+(1-2 \alpha)|z|^{n}\right] /\left(1-|z|^{n}\right) .
\end{aligned}
$$

The inequality (7), because of the last inequality, reduces to

$$
\left|z p^{\prime}(z) / p(z)\right| \leqq 2 n|z|^{n}(1-\alpha) /\left\{\left(1-|z|^{n}\right)\left[1+(1-2 \alpha)|z|^{n}\right]\right\} \text { for }|z|<1
$$

and this completes the proof.

We remark that in the case $\alpha=0$, the above lemma reduces to a result of MacGregor [2; Lemma 1] and the inequality (6) with $\alpha=0, n=1$, gives another result of MacGregor [2, Lemma 2].

LEMMA 3. Under the hypothesis of Lemma 1 we have for $|z|<1$ $\operatorname{Re}(p(z)) \geqq\left[1+(2 \alpha-1)|z|^{n}\right] /\left(1+|z|^{n}\right)$.

Proof. We have from equation (3), $F(z)=[1-h(z)] /[1+h(z)]$ and also from (8), $|h(z)| \leqq|z|^{n}$ for $|z|<1$. Hence the image of $|z|<r(0<r<1)$ under $F(z)$ lies in the interior of the circle with the line segment joining the points $\left(1-r^{n}\right) /\left(1+r^{n}\right)$ and $\left(1+r^{n}\right) /\left(1-r^{n}\right)$ as a diameter. Consequently $\operatorname{Re}(F(z)) \geqq\left(1-|z|^{n}\right) /\left(1+|z|^{n}\right)$ for 
$|z|<1$. The result now follows from the last inequality involving $F(z)$ and equation (2).

LEMMA 4. ([6]). If $h(z)=1+c_{n} z^{n}+c_{n+1} z^{n+1}+\cdots$ is analytic and $\operatorname{Re}(h(z))>0$ for $|z|<1$, then

$$
[1-\lambda|h(z)|]^{-1} \leqq\left(1-|z|^{n}\right) /\left[\left(1-|z|^{n}\right)-\lambda\left(1+|z|^{n}\right)\right]
$$

for $|z|<[(1-\lambda) /(1+\lambda)]^{1 / n}$, where $0 \leqq \lambda<1$.

3. THEOREM 1. Suppose that $f(z)=z+a_{n+1} z^{n+1}+a_{n+2} z^{n+2}+\cdots$, and $g(z)=z+b_{n+1} z^{n+1}+b_{n+2} z^{n+2}+\cdots$ are analytic and $\operatorname{Re}(g(z) / z)>0$ for $|z|<1$. If $\operatorname{Re}(f(z) /[\lambda f(z)+(1-\lambda) g(z)])>0,0 \leqq \lambda<1$, for $|z|<1$, then $f(z)$ is univalent and starlike for $|z|<R^{1 / n}$, where $R=\left\{\left[(2 n+\lambda-n \lambda)^{2}+\left(1-\lambda^{2}\right)\right]^{1 / 2}-(2 n+\lambda-n \lambda)\right\} /(1+\lambda)$.

Proof. Let

$$
h(z)=f(z) /[\lambda f(z)+(1-\lambda) g(z)]=1+c_{n} z^{n}+c_{n+1} z^{n+1}+\cdots,
$$

then $h(z)$ is analytic and $\operatorname{Re}(h(z))>0$ for $|z|<1$. Now

$$
f(z)[1-\lambda h(z)]=(1-\lambda) h(z) z p(z),
$$

where $p(z)=g(z) / z=1+b_{n+1} z^{n}+b_{n+2} z^{n+1}+\cdots$. Multiplying the logarithmic derivative of both sides of equation (10) by $z$ we have

$$
z f^{\prime}(z) / f(z)=1+z p^{\prime}(z) / p(z)+z h^{\prime}(z) /\{h(z)[1-\lambda h(z)]\} .
$$

Equation (11) is valid for those $z$ for which $1-\lambda h(z) \neq 0$ and $|z|<1$. Since $|h(z)| \leqq\left(1+|z|^{n}\right) /\left(1-|z|^{n}\right), 1-\lambda h(z) \neq 0$ in particular if $|z|<[(1-\lambda) /(1+\lambda)]^{1 / n}$. Now from equation (11), we have

$$
\left|z f^{\prime}(z) / f(z)-1\right| \leqq\left|z p^{\prime}(z) / p(z)\right|+\left|z h^{\prime}(z) / h(z)\right||1-\lambda h(z)|^{-1}
$$

and by using Lemma 2 with $\alpha=0$ and Lemma 4, this gives

$$
\begin{aligned}
\left|z f^{\prime}(z) / f(z)-1\right| & \leqq \frac{2 n|z|^{n}}{1-|z|^{2 n}}+\frac{2 n|z|^{n}}{\left(1-|z|^{2 n}\right)-\lambda\left(1+|z|^{n}\right)^{2}}, \\
& =\frac{2 n|z|^{n}\left[\left(1-|z|^{n}\right)-\lambda\left(1+|z|^{n}\right)+\left(1-|z|^{n}\right)\right]}{\left(1-|z|^{2 n}\right)\left[\left(1-|z|^{n}\right)-\lambda\left(1+|z|^{n}\right)\right]}
\end{aligned}
$$

provided that $|z|<[(1-\lambda) /(1+\lambda)]^{1 / n}$.

The fact that $\left|z f^{\prime}(z) / f(z)-1\right|<1$ implies that $\operatorname{Re}\left(z f^{\prime}(z) / f(z)\right)>0$, it follows from the inequality (12) that $\operatorname{Re}\left(z f^{\prime}(z) / f(z)>0\right.$ if

$$
|z|<[(1-\lambda) /(1+\lambda)]^{1 / n}
$$

and if 


$$
\begin{aligned}
G\left(|z|^{n}\right) \equiv & (1+\lambda)|z|^{3 n}+(4 n+2 n \lambda+\lambda-1)|z|^{2 n} \\
& +(2 n \lambda-4 n-\lambda-1)|z|^{n}+(1-\lambda)>0 .
\end{aligned}
$$

Let $|z|^{n}=t$ and consider the cubic polynomial $G(t)$ for $0 \leqq t \leqq 1$. $G(t)$ has at most two positive zeros. Since $G(0)=(1-\lambda)>0$, $G[(1-\lambda) /(1+\lambda)]=-4 \lambda n(1-\lambda) /(1+\lambda)^{2}<0$ and $G(1)=4 \lambda n>0$, it follows that $G\left(t_{1}\right)=0$ for some $t_{1}$ such that $0<t_{1}<(1-\lambda) /(1+\lambda)$ and $G(t)>0$ for $0 \leqq t<t_{1}$ and $G(t)<0$ for $t_{1}<t<(1-\lambda) /(1+\lambda)$. Hence $\operatorname{Re}\left(z f^{\prime}(z) / f(z)\right)>0$ for those $z$ for which only the inequality (13) is true. Now the inequality (13) holds if, in particular

$$
\begin{aligned}
(1+\lambda)|z|^{3 n} & +(4 n-2 n \lambda+\lambda-1)|z|^{2 n} \\
& +(2 n \lambda-4 n-\lambda-1)|z|^{n}+(1-\lambda)>0
\end{aligned}
$$

or,

$$
\left(|z|^{n}-1\right)\left[(1+\lambda)|z|^{2 n}+(4 n-2 n \lambda+2 \lambda)|z|^{n}+(\lambda-1)\right]>0
$$

or,

$$
(1+\lambda)|z|^{2 n}+(4 n-2 n \lambda+2 \lambda)|z|^{n}+(\lambda-1)<0 .
$$

The last inequality holds if

$$
|z|^{n}<\left\{\left[(2 n+\lambda-n \lambda)^{2}+\left(1-\lambda^{2}\right)\right]^{1 / 2}-(2 n+\lambda-n \lambda)\right\} /(1+\lambda) .
$$

Since $f(z)$ is univalent and starlike for those $z$ for which

$$
\operatorname{Re}\left(z f^{\prime}(z) / f(z)\right)>0,
$$

we have that $f(z)$ is univalent and starlike for $|z|<R^{1 / n}$, where $R$ is the right side of (14).

If we put $\lambda=0$ in Theorem 1 we obtain the following result which, when $n=1$, reduces to a result of Ratti [5, Theorem 1].

CoROLlaRY 1. Suppose that $f(z)=z+a_{n+1} z^{n+1}+a_{n+2} z^{n+2} \cdots$, and $g(z)=z+b_{n+1} z^{n+1}+b_{n+2} z^{n+2}+\cdots$ are analytic and $\operatorname{Re}(g(z) / z)>0$ for $|z|<1$. If $\operatorname{Re}(f(z) / g(z))>0$ for $|z|<1$ then $f(z)$ is univalent and starlike for $|z|<\left[\left(4 n^{2}+1\right)^{1 / 2}-2 n\right]^{1 / n}$.

The functions $f(z)=z\left(1-z^{n}\right)^{2} /\left(1+z^{n}\right)^{2}$ and $g(z)=z\left(1-z^{n}\right) /\left(1+z^{n}\right)$ satisfy the hypothesis of Corollary 1 and it is easy to see that the derivative of $f(z)$ vanishes at $z=\left[\left(4 n^{2}+1\right)^{1 / 2}-2 n\right]^{1 / n}$ and hence $\left[\left(4 n^{2}+1\right)^{1 / 2}-2 n\right]^{1 / n}$ is in fact the radius of univalence for such functions $f(z)$. This shows that Corollary 1 is sharp and hence Theorem 1 is sharp at least for $\lambda=0$.

TheOREM 2. Suppose $f(z)=z+a_{2} z^{2}+\cdots$, and 


$$
g(z)=z+b_{2} z^{2}+\cdots
$$

are analytic for $|z|<1$ and $\operatorname{Re}(g(z) / z)>1 / 2$ for $|z|<1$. If

$$
\operatorname{Re}(f(z) /[\lambda f(z)+(1-\lambda) g(z)])>0 \quad \text { for }|z|<1
$$

then $f(z)$ is univalent and starlike for $|z|<(1-\lambda) /(3+\lambda)$.

Proof. Let $h(z)=f(z) /[\lambda f(z)+(1-\lambda) g(z)]=1+c_{1} z+c_{2} z^{2}+\cdots$. Now $h(z)$ is analytic and $\operatorname{Re}(h(z))>0$ for $|z|<1$ and

$$
f(z)[1-\lambda h(z)]=(1-\lambda) h(z) g(z) \text {. }
$$

If we let $g(z)=z p(z)$, then by applying Lemma 1 with $\alpha=1 / 2$ and $n=1$ we have that $p(z)=[1+z u(z)]^{-1}$, where $u(z)$ is analytic and $|u(z)| \leqq 1$ for $|z|<1$. Equation (15) now reduces to

$$
f(z)[1-\lambda h(z)]=(1-\lambda) z h(z) /[1+z u(z)] \text {. }
$$

Hence

$$
\frac{z f^{\prime}(z)}{f(z)}=\frac{1-z^{2} u^{\prime}(z)}{1+z u(z)}+\frac{z h^{\prime}(z)}{h(z)[1-\lambda h(z)]}
$$

and

$$
\operatorname{Re}\left(\frac{z f^{\prime}(z)}{f(z)}\right) \geqq \operatorname{Re}\left(\frac{1-z^{2} u^{\prime}(z)}{1+z u(z)}\right)-\frac{\left|z h^{\prime}(z) / h(z)\right|}{|1-\lambda h(z)|}
$$

Using Lemmas 2 and 4 with $n=1$, we get

$$
\operatorname{Re}\left(\frac{z f^{\prime}(z)}{f(z)}\right) \geqq \operatorname{Re}\left(\frac{1-z^{2} u^{\prime}(z)}{1+z u(z)}\right)-\frac{2|z|}{\left(1-|z|^{2}\right)-\lambda\left(1+|z|^{2}\right.}
$$

for $|z|<(1-\lambda) /(1+\lambda)$.

Hence $\operatorname{Re}\left(z f^{\prime}(z) / f(z)\right)>0$ if $|z|<(1-\lambda) /(1+\lambda)$ and $T(|z|) \operatorname{Re}\left[\left(1-z^{2} u^{\prime}(z)\right)(1+\overline{z u(z)}]-2|z| \operatorname{Re}[(1+z u(z))(1+\overline{z u(z)}]>0\right.$, where $T(|z|)=\left(1-|z|^{2}\right)-\lambda(1+|z|)^{2}$. The last inequality holds if

$$
\begin{aligned}
& T(|z|) \operatorname{Re}(1+\overline{z u(z)})-T(|z|) \operatorname{Re}\left[z^{2} u^{\prime}(z)(1+\overline{z u(z)}]\right. \\
& \quad+2|z| \operatorname{Re}[(1-z u(z))(1+\overline{z u(z)})]-4|z| \operatorname{Re}(1+\overline{z u(z)})>0,
\end{aligned}
$$

or if

$$
\begin{aligned}
& {[4|z|-T(|z|)] \operatorname{Re}(1+\overline{z u(z)})+T(|z|) \operatorname{Re}\left[z^{2} u^{\prime}(z)(1+\overline{z u(z)})\right]} \\
& <2|z|\left(1-|z|^{2}|u(z)|^{2}\right)
\end{aligned}
$$

or 


$$
\begin{aligned}
& |4| z|-T(|z|)|(1+|z||u(z)|)+T(|z|)|z|^{2}\left|u^{\prime}(z)\right|(1+|z||u(z)|) \\
& <2|z|\left(1-|z|^{2}|u(z)|^{2}\right) .
\end{aligned}
$$

This inequality holds, in view of (5) with $n=1$ if

$$
\begin{aligned}
& |4| z|-T(|z|)|+T(|z|)|z|^{2}\left(1-|u(z)|^{2}\right)\left(1-|z|^{2}\right)^{-1} \\
& <2|z|(1-|z||u(z)|) .
\end{aligned}
$$

Two cases arise according as $4|z|-T(|z|)$ is nonnegative or not.

Case 1. $4|z|-T(|z|) \geqq 0$, i.e. $|z| \geqq\left[(4 \lambda+5)^{1 / 2}-(\lambda+2)\right] /(1+\lambda)$. Since $\left[(4 \lambda+5)^{1 / 2}-(\lambda+2)\right]<(1-\lambda)$ for $0 \leqq \lambda<1$, it follows, in view of inequality (16), that $\operatorname{Re}\left(z f^{\prime}(z) / f(z)\right)>0$ for those $z$ for which $\left[(4 \lambda+5)^{1 / 2}-(\lambda+2)\right] /(1+\lambda) \leqq|z|<(1-\lambda) /(1+\lambda)$ and

$$
\begin{aligned}
& 4|z|-T(|z|)+T(|z|)|z|^{2}\left(1-|u(z)|^{2}\right)\left(1-|u(z)|^{2}\right)^{-1} \\
& <2|z|(1-|z||u(z)|) .
\end{aligned}
$$

The last inequality holds, because of the original value of $T(|z|)$, if

$$
\begin{aligned}
& 2|z|+2|z|^{2}-1+\lambda(1+|z|)^{2}-\lambda|z|^{2}(1+|z|) /(1-|z|) \\
& <|z|^{2}|u(z)|^{2}-\lambda|z|^{2}|u(z)|^{2}(1+|z|) /(1-|z|)-2|z|^{2}|u(z)| \cdot
\end{aligned}
$$

Since $|u(z)| \leqq 1$, the right side of inequality (17)

$$
\geqq|z|^{2}|u(z)|^{2}-2|z|^{2}|u(z)|-\lambda|z|^{2}(1+|z|) /(1-|z|) .
$$

Hence inequality (17) holds, if in particular

$$
2|z|+2|z|^{2}-1+\lambda(1+|z|)^{2}<|z|^{2}|u(z)|^{2}-2|z|^{2}|u(z)| \cdot
$$

If we let $F(x)=x^{2}|z|^{2}-2 x|z|^{2}$, where $x=|u(z)|, 0 \leqq x \leqq 1$, then $F(x)$ is a decreasing function of $x$ for $0 \leqq x \leqq 1$, and hence

$$
F(x) \geqq F(1)=-|z|^{2} \quad \text { for } 0 \leqq x \leqq 1 \text {. }
$$

Hence inequality (18) holds if $2|z|+2|z|^{2}-1+\lambda(1+|z|)^{2}<-|z|^{2}$ or $(3|z|-1)(|z|+1)+\lambda(1+|z|)^{2}<0$ or $3|z|-1+\lambda(1+|z|)<0$ or if $|z|<(1-\lambda) /(3+\lambda)$. Since $(1-\lambda) /(3+\lambda)<(1-\lambda) /(1+\lambda)$, we have shown that

$$
\begin{aligned}
& \operatorname{Re}\left(z f^{\prime}(z) / f(z)\right)>0 \\
& \text { for }\left[(4 \lambda+5)^{1 / 2}-(\lambda+2)\right] /(1+\lambda) \leqq|z|<(1-\lambda) /(3+\lambda) .
\end{aligned}
$$

Case 2. $4|z|-T(|z|)<0$, i.e. $|z|<\left[(4 \lambda+5)^{1 / 2}-(\lambda+2)\right] /(1+\lambda)$. We intend to show that $\operatorname{Re}\left(z f^{\prime}(z) / f(z)\right)>0$ in this case also. Since $f(z)$ and $g(z)$ satisfy, in particular, the hypothesis of Theorem 1 with $n=1$, it follows from Theorem 1 that 


$$
\operatorname{Re}\left(z f^{\prime}(z) / f(z)\right)>0 \text { for }|z|<\left[\left(5-\lambda^{2}\right)^{1 / 2}-2\right] /(1+\lambda) \text {. }
$$

It is easy to see that

$$
\left[(4 \lambda+5)^{1 / 2}-(\lambda+2)\right] \leqq\left(5-\lambda^{2}\right)^{1 / 2}-2 \text { for } 0 \leqq \lambda \leqq 1
$$

and hence in particular

$$
\operatorname{Re}\left(z f^{\prime}(z) / f(z)\right)>0 \text { for }|z|<\left[(4 \lambda+5)^{1 / 2}-(\lambda+2)\right] /(1+\lambda) .
$$

In view of the above and (19), it now follows that $f(z)$ is univalent and starlike for $|z|<(1-\lambda) /(3+\lambda)$ and this completes the proof.

For $\lambda=0$ the above result reduces to a result of Ratti [5, Theorem 2] and improves a result of MacGregor [2, Theorem 4] since $\operatorname{Re}(g(z) / z)>1 / 2$ does not necessarily imply that $g(z)$ is convex [7]. The functions $f(z)=z(1-z) /(1+z)^{2}$ and $g(z)=z /(1+z)$ satisfy the hypothesis of Theorem 2 with $\lambda=0$ and $f(z)$ is univalent in no circle $|z|<r$ with $r>1 / 3$ since $f^{\prime}(z)$ vanishes at $z=1 / 3$. This shows that Theorem 2 is sharp at least for $\lambda=0$.

A function $f(z)=z+\sum_{k=2}^{\infty} a_{k} z^{k}$ is said to be starlike of order $\alpha$, $0 \leqq \alpha<1$, for $|z|<1$ if $\operatorname{Re}\left(z f^{\prime}(z) / f(z)\right)>\alpha$ for $|z|<1$, we now prove the following result.

THEOREM 3. Let $f(z)=z+\sum_{k=n+1}^{\infty} b_{k} z^{k}$ and $g(z)=z+\sum_{k=n+1}^{\infty} b_{k} z^{k}$ be analytic for $|z|<1$ and $g(z)$ be starlike of order $\alpha, 0 \leqq \alpha<1$, for $|z|<1$. If $\operatorname{Re}(f(z) /[\lambda f(z)+(1-\lambda) g(z)])>0$ for $|z|<1$, then $f(z)$ is univalent and starlike for

$$
|z|<[(1-\lambda) /(1+\lambda+2 n)]^{1 / n} \quad \text { if } \alpha=1 / 2 ;
$$

and

$$
|z|<R^{1 / n}, \quad \text { if } \alpha \neq 1 / 2,
$$

where

$$
R=\left\{\left[A^{2}+4\left(1-\lambda^{2}\right)(2 \alpha-1)\right]^{1 / 2}-A\right\} /[2(1+\lambda)(2 \alpha-1)]
$$

with $A=2 n+\lambda+1-(2 \alpha-1)(1-\lambda)$.

Proof. Proceeding as in the proof of Theorem 1 we get

$$
\operatorname{Re}\left(z f^{\prime}(z) / f(z)\right) \geqq \operatorname{Re}\left(z g^{\prime}(z) / g(z)\right)-\left|z h^{\prime}(z) / h(z)\right||1-\lambda h(z)|^{-1} \cdot
$$

Applying Lemma 3 (to $z g^{\prime}(z) / g(z)$ ) and Lemmas 2 and 4 we get,

$$
\operatorname{Re}\left(\frac{z f^{\prime}(z)}{f(z)}\right) \geqq \frac{1+(2 \alpha-1)|z|^{n}}{1+|z|^{n}}-\frac{2 n|z|^{n}}{\left(1-|z|^{2 n}\right)-\lambda\left(1+|z|^{n}\right)^{2}}
$$

provided that $|z|<[(1-\lambda) /(1+\lambda)]^{1 / n}$. 
Hence $\operatorname{Re}\left(z f^{\prime}(z) / f(z)\right)>0$ for those $z$ for which $\left.|z|<[1-\lambda) /(1+\lambda)\right]^{1 / n}$ and the right side of inequality (20) is greater than zero. The latter holds if

$$
\begin{aligned}
G\left(|z|^{n}\right) \equiv & (1+\lambda)(2 \alpha-1)|z|^{2 n} \\
& +[2 n+\lambda+1-(2 \alpha-1)(1-\lambda)]|z|^{n}-(1-\lambda)<0 .
\end{aligned}
$$

Let $|z|^{n}=t$ and consider the quadratic $G(t)$ for $0 \leqq t \leqq 1$. Since $G(0)=\lambda-1<0, G[(1-\lambda) /(1+\lambda)]=2 n(1-\lambda) /(1+\lambda)>0$, it follows that $G\left(t_{1}\right)=0$ for some $t_{1}$ such that $0<t_{1}<(1-\lambda) /(1+\lambda)$ and $G(t)<0$ for $0 \leqq t<t_{1}$ and $G(t)>0$ for $t_{1}<t<(1-\lambda) /(1+\lambda)$. Hence $f(z)$ is univalent and starlike for those $z$ for which only the inequality (21) holds. Now the inequality (21) holds if

$$
|z|<[(1-\lambda) /(1+\lambda+2 n)]^{1 / n}
$$

when $\alpha=1 / 2$ and

$$
|z|<\left\{\left[A^{2}+4\left(1-\lambda^{2}\right)(2 \alpha-1)\right]^{1 / 2}-A\right\}^{1 / n} /[2(1+\lambda)(2 \alpha-1)]^{1 / n}
$$

when $\alpha \neq 1 / 2$, where $A=2 n+\lambda+1-(2 \alpha-1)(1-\lambda)$ and this completes the proof.

If we put $\lambda=0, n=1$ and $\alpha=0$ in the above result then we see that $f(z)=z+\sum_{k=2}^{\infty} a_{k} z^{k}$ under the modified hypothesis is univalent and starlike for $|z|<2-\sqrt{3}$, a result obtained by MacGregor [2, Theorem 3]. On the other hand if $\lambda=0$ and $n=1$, Theorem 3 reduces to a result of Ratti [5, Theorem 3]. The functions

$$
f(z)=z\left(1-z^{n}\right) /\left(1+z^{n}\right)^{\frac{2-2 \alpha}{n}+1} \text { and } g(z)=z /\left(1+z^{n}\right)^{\frac{2-2 \alpha}{n}}
$$

show that Theorem 3 is sharp at least for $\lambda=0$ and arbitrary $n$, since the derivative of $f(z)$ vanishes at

$$
z=\left\{\left[(n+1-\alpha)-\left((n+1-\alpha)^{2}-(1-2 \alpha)\right)^{1 / 2}\right] /(1-2 \alpha)\right\}^{1 / n}
$$

for $\alpha \neq 1 / 2$ and at $z=-1 /(2 n+1)$ when $\alpha=1 / 2$.

4. Let $S(R)$ denote the functions $f(z)=z+\sum_{k=2}^{\infty} \alpha_{k} z^{k}$ which are analytic and satisfy $\left|z f^{\prime}(z) / f(z)-1\right|<1$ for $|z|<R$. Obviously every member of $S(R)$ is univalent and starlike for $|z|<R$. We now prove the following result.

THEOREM 4. Let $f(z)=z+a_{n+1} z^{n+1}+a_{n+2} z^{n+2}+\cdots$, and $g(z)=$ $z+b_{n+1} z^{n+1}+b_{n+2} z^{n+2}+\cdots$ be analytic and satisfy $\operatorname{Re}(g(z) / z)>0$ for $|z|<1$. If $|f(z) /[\lambda f(z)+(1-\lambda) g(z)]-1|<1,0 \leqq \lambda<1$, for $|z|<1$, then $f(z) \in S\left(R^{1 / n}\right)$, where $R$ is the smallest positive root of the equation $(2 n \lambda+\lambda-n-1) R^{2}-(3 n+\lambda-2 n \lambda) R+(1-\lambda)=0$. 


\section{Proof. Let}

$$
h(z)=f(z) /[\lambda f(z)+(1-\lambda) g(z)]-1=c_{n} z^{n}+c_{n+1} z^{n+1}+\cdots .
$$

By hypothesis, $h(z)$ is analytic and $|h(z)|<1$ for $|z|<1$ and hence by a result of Goluzin [1] we have that for $|z|<1$

$$
\left|h^{\prime}(z)\right| \leqq n|z|^{n-1}\left(1-|h(z)|^{2}\right) /\left(1-|z|^{2 n}\right)
$$

and by Schwarz's lemma for $|z|<1$

$$
|h(z)| \leqq|z|^{n}
$$

If we let $g(z)=z p(z)$, then we have from (22)

$$
f(z)[1-\lambda-\lambda h(z)]=(1-\lambda) z p(z)[1+h(z)] .
$$

Hence,

$$
\frac{z f^{\prime}(z)}{f(z)}=1+\frac{z p^{\prime}(z)}{p(z)}+\frac{z h^{\prime}(z)}{[1+h(z)][1-\lambda-\lambda h(z)]}
$$

and this gives

$$
\left|\frac{z f^{\prime}(z)}{f(z)}-1\right| \leqq\left|\frac{z p^{\prime}(z)}{p(z)}\right|+\frac{\left|z h^{\prime}(z)\right|}{|1+h(z)||1-\lambda-\lambda h(z)|} .
$$

Applying Lemma 2, with $\alpha=0$, we get, in view of (23), for $|z|<1$

$$
\begin{aligned}
\left|\frac{z f^{\prime}(z)}{f(z)}-1\right| & \leqq \frac{2 n|z|^{n}}{1-|z|^{2 n}}+\frac{n|z|^{n}\left(1-|h(z)|^{2}\right)}{\left(1-|z|^{2 n}\right)|1+h(z)||1-\lambda-\lambda h(z)|} \\
& \leqq \frac{2 n|z|^{n}}{1-|z|^{2 n}}+\frac{n|z|^{n}(1+|h(z)|)}{\left(1-|z|^{2 n}\right)|1-\lambda-\lambda h(z)|}
\end{aligned}
$$

by using (24), we have

$$
\left|\frac{z f^{\prime}(z)}{f(z)}-1\right| \leqq \frac{2 n|z|^{n}}{1-|z|^{2 n}}+\frac{n|z|^{n}}{\left(1-|z|^{n}\right)\left(1-\lambda-\lambda|z|^{n}\right)}
$$

valid for $|z|<[(1-\lambda) / \lambda]^{1 / n}$. Hence $\left|z f^{\prime}(z) / f(z)-1\right|<1$ if

$$
|z|<[(1-\lambda) / \lambda]^{1 / n}
$$

and

$$
2 n|z|^{n}\left(1-\lambda-\lambda|z|^{n}\right)+n|z|^{n}\left(1+|z|^{n}\right)<\left(1-|z|^{2 n}\right)\left(1-\lambda-\lambda|z|^{n}\right) .
$$

The last inequality holds if

$$
\begin{aligned}
G\left(|z|^{n}\right) \equiv & \lambda|z|^{3 n}+(2 n \lambda+\lambda-n-1)|z|^{2 n} \\
& -(3 n+\lambda-2 n \lambda)|z|^{n}+(1-\lambda)>0 .
\end{aligned}
$$

Let $|z|^{n}=t$ and consider the cubic polynomial $G(t)$ for $0 \leqq t \leqq 1$. 
$G(t)$ has at most two positive zeros. Since $G(0)=(1-\lambda)>0$ and $G((1-\lambda) / \lambda)=-\left(n(1-\lambda) / \lambda^{2}<0\right.$, it follows that $G\left(t_{1}\right)=0$ for some $t_{1}$ such that $0<t_{1}<(1-\lambda) / \lambda$ and $G(t)>0$ for $0 \leqq t<t_{1}$ and $G(t)<0$ for some values of $t$ between $t_{1}$ and $(1-\lambda) / \lambda$. Hence

$$
\left|z f^{\prime}(z) / f(z)-1\right|<1
$$

for those values of $z$ for which only the inequality (25) holds. Now inequality (25) holds if, in particular

$$
(2 n \lambda+\lambda-n-1)|z|^{2 n}-(3 n+\lambda-2 n \lambda)|z|^{n}+(1-\lambda)>0
$$

and this completes the proof.

If we set $\lambda=0$ and $n=1$ in the above result we have the following.

COROLLARY 2. Suppose $f(z)=z+a_{2} z^{2}+a_{3} z^{3}+\cdots$ and $g(z)=$ $z+b_{2} z^{2}+b_{3} z^{3}+\cdots$ are analytic and satisfy $\operatorname{Re}(g(z) / z)>0$ for $|z|<1$. If $|f(z) / g(z)-1|<1$ for $|z|<1$, then $\left|z f^{\prime}(z) / f(z)-1\right|<1$ for $|z|<1 / 4(\sqrt{17}-3)$.

It may be noted that Corollary 2 implies, in particular, that $f(z)$ is univalent and starlike for $|z|<1 / 4(\sqrt{17}-3)$ and hence includes a result of Ratti [5, Theorem 4]. If we take $f(z)=z\left(1-z^{n}\right)^{2} /\left(1+z^{n}\right)$ and $g(z)=z\left(1-z^{n}\right) /\left(1+z^{n}\right)$, it is easy to see that these functions satisfy the hypothesis of Theorem 4 with $\lambda=0$. We see that $f^{\prime}(z)$ vanishes at $z_{0}=\left[-3 n+\left(9 n^{2}+4 n+4\right)^{1 / 2}\right] /(2 n+2)$ and hence

$$
\left|z_{0} f^{\prime}\left(z_{0}\right) / f\left(z_{0}\right)-1\right|=1 \text {. }
$$

This shows that Theorem 4 is sharp for at least $\lambda=0$ and also that Corollary 2 is sharp.

THEOREM 5. Let $f(z)=z+a_{n+1} z^{n+1}+a_{n+2} z^{n+2}+\cdots$ and $g(z)=$ $z+b_{n+1} z^{n+1}+b_{n+2} z^{n+2}+\cdots$ be analytic for $|z|<1$ and $g(z)$ be starlike of order $\alpha$ for $|z|<1,0 \leqq \alpha<1$. If

$$
\mid f(z) /[\lambda f(z)+(1-\lambda) g(z)]-1<1,0 \leqq \lambda<1, \text { for }|z|<1,
$$

then $f(z)$ is univalent and starlike for $|z|<R^{1 / n}$, where $R$ is the smallest positive root of the equation

$$
\begin{aligned}
(2 \alpha-1) \lambda R^{3} & -(n+2 \alpha-1-\lambda) R^{2} \\
+ & (2 \alpha-2-2 \alpha \lambda+\lambda-n) R+(1-\lambda)=0 .
\end{aligned}
$$

Proof. Proceeding as in the proof of Theorem 4 we have 


$$
\frac{z f^{\prime}(z)}{f(z)}=\frac{z g^{\prime}(z)}{g(z)}+\frac{z h^{\prime}(z)}{[1+h(z)][1-\lambda-\lambda h(z)]} .
$$

Hence,

$$
\operatorname{Re}\left(\frac{z f^{\prime}(z)}{f(z)}\right) \geqq \operatorname{Re}\left(\frac{z g^{\prime}(z)}{g(z)}\right)-\frac{\left|z h^{\prime}(z)\right|}{|1+h(z)||1-\lambda-\lambda h(z)|} .
$$

Since $\operatorname{Re}\left(z g^{\prime}(z) / g(z)\right)>\alpha$ and $z g^{\prime}(z) / g(z)=1+c_{n} z^{n}+c_{n+1} z^{n+1}+\cdots$, we have by Lemma 3 and inequalities (23) and (24) that

$$
\begin{aligned}
\operatorname{Re}\left(z f^{\prime}(z) / f(z)\right) \geqq & {\left[1+(2 \alpha-1)|z|^{n}\right] /\left(1+|z|^{n}\right) } \\
& -n|z|^{n} /\left[\left(1-|z|^{n}\right)\left(1-\lambda-\lambda|z|^{n}\right)\right]
\end{aligned}
$$

valid for $|z|<[(1-\lambda) / \lambda]^{1 / n}$.

Hence $\operatorname{Re}\left(z f^{\prime}(z) / f(z)\right)>0$ if $|z|<[(1-\lambda) / \lambda]^{1 / n}$ and if (in view of inequality (27))

$$
\begin{aligned}
G\left(|z|^{n}\right) \equiv & (2 \alpha-) \lambda|z|^{3 n} \\
& -(n+2 \alpha-1-\lambda)|z|^{2 n} \\
& +(2 \alpha-2-2 \alpha \lambda+\lambda-n)|z|^{n} \\
& +(1-\lambda)>0
\end{aligned}
$$

Let $|z|=t$ and consider the cubic polynomial $G(t)$ for $0 \leqq t \leqq 1$. Since $G(0)=1-\lambda>0$ and $G((1-\lambda) / \lambda)=(-n(1-\lambda)) / \lambda^{2}<0$, it follows that $G\left(t_{1}\right)=0$ for some $t_{1}$ such that $0<t_{1}<(1-\lambda) / \lambda$ and $G(t)>0$ for $0 \leqq t<t_{1}$ and $G(t)<0$ for some $t$ between $t_{1}$ and $(1-\lambda) / \lambda$. Hence $f(z)$ is starlike and univalent for $|z|<R^{1 / n}$, in view of inequality (28), where $R$ is the smallest positive root of the equation (26).

The case when $\lambda=0$ in Theorem 5 is of special interest. In this case equation (26) becomes

$$
(n+2 \alpha-1) R^{2}-(2 \alpha-2-n) R-1=0
$$

which gives $R=1 / 3$ in case $\alpha=0$ and $n=1$ and

(29) $R=\left\{(2 \alpha-2-n)+\left[(2 \alpha-2-n)^{2}+4(n+2 \alpha-1)\right]^{1 / 2}\right\} /[2(n+2 \alpha-1)]$

if $\alpha \neq 0$. This proves the following result, which includes a result of Ratti [5, Theorem 6].

CoRollaRy 3. Suppose $f(z)=z+a_{n+1} z^{n+1}+a_{n+2} z^{n+2}+\cdots$ and $g(z)=z+b_{n+1} z^{n+1}+b_{n+2} z^{n+2}+\cdots$ are analytic for $|z|<1$ and $g(z)$ is starlike of order $\alpha$ for $|z|<1,0 \leqq \alpha<1$. If $|f(z) / g(z)-1|<1$ for $|z|<1$ then $f(z)$ is univalent and starlike for

(i) $|z|<1 / 3$ if $\alpha=0$ and $n=1$ 
(ii) $|z|<R^{1 / n}$, where $R$ is given by (29) if $\alpha \neq 0$.

It is easy to see that the functions $f(z)=z\left(1-z^{n}\right) /\left(1+z^{n}\right)^{(2-2 \alpha) / n}$ and $g(z)=z /\left(1+z^{n}\right)^{(2-2 \alpha) / n}$ satisfy the hypothesis of Corollary 3 and also that the derivative of $f(z)$ vanishes at $z=1 / 3$ if $\alpha=0$ and $n=1$, and at $z=\left\{\left[(n+2-2 \alpha)^{2}+4(n+2 \alpha-1)\right]^{1 / 2}-(n+2-2 \alpha)\right\}^{1 / n} /$ $[2(n+2 \alpha-1)]^{1 / n}$ if $\alpha \neq 0$. This shows that Corollary 3 is sharp.

\section{REFERENCES}

1. G. M. Goluzin, Some estimates of derivatives of bounded functions, Mat. Sb., N.S., 16 (1945), 295-306.

2. T. H. MacGregor, The radius of univalence of certain analytic functions, Proc. Amer. Math. Soc., 14 (1963), 514-520.

3 . - The radius of univalence of certain analytic functions, II., Proc. Amer. Math. Soc., 14 (1963), 521-524.

4. Z. Nehari, Conformal Mapping, First Ed., 1952, McGraw Hill Inc., New York.

5. J. S. Ratti, The radius of univalence of certain analytic functions, Math. Z. 107 (1968), 241-248.

6. G. M. Shah, The Radius of p-valence of some analytic functions, submitted to Czechoslovak Math. J.

7. E. Strohhäcker, Beiträge Zu Theorie der Schlichten Funktionen, Math. Z., 37 (1933), $356-380$.

Received July 1, 1971 and in revised form January 28, 1972. This research was supported in part by a grant from the Research Committee of the University of Wisconsin Center System.

ThE UNIVERSity OF WISCONSIN - WAUKESHA 


\section{PACIFIC JOURNAL OF MATHEMATICS}

\section{EDITORS}

\section{H. SAMElson}

Stanford University

Stanford, California 94305

C. R. Новву

University of Washington

Seattle, Washington 98105
J. DugunduI

Department of Mathematics University of Southern California

Los Angeles, California 90007

RICHARD ARENS

University of California

Los Angeles, California 90024

\section{ASSOCIATE EDITORS}
E. F. BECKENBACH
B. H. NeUmanN
F. WOLF
K. YosHIDA

\section{SUPPORTING INSTITUTIONS}

UNIVERSITY OF BRITISH COLUMBIA

UNIVERSITY OF SOUTHERN CALIFORNIA

CALIFORNIA INSTITUTE OF TECHNOLOGY

STANFORD UNIVERSITY

UNIVERSITY OF CALIFORNIA

UNIVERSITY OF TOKYO

MONTANA STATE UNIVERSITY

UNIVERSITY OF UTAH

UNIVERSITY OF NEVADA

WASHINGTON STATE UNIVERSITY

NEW MEXICO STATE UNIVERSITY

OREGON STATE UNIVERSITY

UNIVERSITY OF OREGON

OSAKA UNIVERSITY

UNIVERSITY OF WASHINGTON

* *

AMERICAN MATHEMATICAL SOCIETY

NAVAL WEAPONS CENTER 


\section{Pacific Journal of Mathematics}

\section{Vol. 43, No. $1 \quad$ March, 1972}

Alexander (Smbat) Abian, The use of mitotic ordinals in cardinal

arithmetic ....................................... 1

Helen Elizabeth. Adams, Filtrations and valuations on rings ......... 7

Benno Artmann, Geometric aspects of primary lattices .............. 15

Marilyn Breen, Determining a polytope by Radon partitions ........... 27

David S. Browder, Derived algebras in $L_{1}$ of a compact group .......... 39

Aiden A. Bruen, Unimbeddable nets of small deficiency .............. 51

Michael Howard Clapp and Raymond Frank Dickman, Unicoherent

compactifications ............................... 55

Heron S. Collins and Robert A. Fontenot, Approximate identities and the strict topology ................................... 63

R. J. Gazik, Convergence in spaces of subsets................. 81

Joan Geramita, Automorphisms on cylindrical semigroups ........... 93

Kenneth R. Goodearl, Distributing tensor product over direct product ..... 107

Julien O. Hennefeld, The non-conjugacy of certain algebras of

operators ................................... 111

C. Ward Henson, The nonstandard hulls of a uniform space ........... 115

M. Jeanette Huebener, Complementation in the lattice of regular

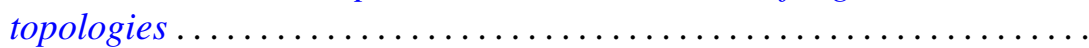

Dennis Lee Johnson, The diophantine problem $Y^{2}-X^{3}=A$ in a

polynomial ring .................................... 151

Albert Joseph Karam, Strong Lie ideals . . . . . . . . . . . . . . . . . . . . 157

Soon-Kyu Kim, On low dimensional minimal sets ............... 171

Thomas Latimer Kriete, III and Marvin Rosenblum, A Phragmén-Lindelöf

theorem with applications to $M(u, v)$ functions ..... . .

William A. Lampe, Notes on related structures of a universal algebra . . . . 189

Theodore Windle Palmer, The reducing ideal is a radical .

207

Kulumani M. Rangaswamy and N. Vanaja, Quasi projectives in abelian and module categories ................................ 221

Ghulam M. Shah, On the univalence of some analytic functions ......... 239

Joseph Earl Valentine and Stanley G. Wayment, Criteria for Banach

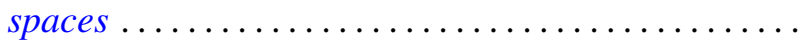

Jerry Eugene Vaughan, Linearly stratifiable spaces ............... 253

Zbigniew Zielezny, On spaces of distributions strongly regular with respect to partial differential operators ..................... 